\title{
ESTROM 2008 International Conference
}

\section{Other Journal Item}

\section{Author(s):}

Giger, Walter; Bloesch, Juerg; Zobrist, Juerg

Publication date:

2009-08

Permanent link:

https://doi.org/10.3929/ethz-b-000083156

\section{Rights / license:}

In Copyright - Non-Commercial Use Permitted

\section{Originally published in:}

Environmental Science and Pollution Research 16(1 Supplement), https://doi.org/10.1007/s11356-009-0206-5 


\title{
ESTROM 2008 International Conference
}

\author{
Walter Giger • Jürg Bloesch • Jürg Zobrist
}

Received: 26 May 2009/Accepted: 28 May 2009 / Published online: 19 June 2009

(C) Springer-Verlag 2009

As a final event of the Romanian-Swiss collaborative research program ESTROM (Environmental Science and Technology in ROMania), the International ESTROM Conference "Environmental Research and Mitigation of Water Pollution in Romania and in the Lower Danube Region" was held 3-5 September 2008 at the Romanian Academy in Bucharest, Romania. The key questions to be addressed were:

- What can the ESTROM projects contribute to implement the EU Water Framework Directive (WFD) in the Lower Danube Region?

- How can an integrated water management (river basin management) be performed in the Lower Danube Region?

- What can be learnt from experiences in other European regions, for example in the Rhine River Basin?

The target audience for the conference was environmental scientists and engineers, water managers, and environment and health authorities. In addition, organizations dealing with the protection of water bodies, e.g., the International Commission for the Protection of the Danube River (ICPDR), stakeholders, nongovernmental organizations, decision makers, and drinking water suppliers, were addressed.

Responsible editor: Walter Giger

W. Giger $(\bowtie)$

GRC - Giger Research Consulting,

8049 Zurich, Switzerland

e-mail: giger@giger-research.ch

W. Giger $\cdot$ J. Bloesch $\cdot$ J. Zobrist

Eawag-Swiss Federal

Institute of Aquatic Science and Technology,

8600 Dübendorf, Switzerland
The Organizing Committee consisted of Walter Giger, Jürg Bloesch, and Jürg Zobrist (Eawag, Dübendorf, Switzerland), Nicolae Panin and Alina Pavel (Institute GeoEcoMar, Bucharest, Romania), Viorel Ungureanu (University of Bucharest, Romania), Elisabeth Schenker (Swiss National Science Foundation, Bern, Switzerland), and Paolo Demaria (Demaria Event Management, Zurich, Switzerland).

Summarized oral reports of the nine ESTROM projects concerning contaminants in wastewaters, surface waters and sediments, and drinking waters of Romania, monitoring and mitigation of pollution, and implementation of respective measures were also presented. The conference was opened by Prof. Anton Anton, State Secretary of the Romanian Ministry of Education, Research and Youth and President of the National Authority of Scientific Research. He welcomed 120 participants from 17 countries (Fig. 1) and reflected in his lively speech on the special current situation of research activities in Romania. Dr. Simon Geissbühler, Chargé d'affaires of the Swiss Embassy in Romania, emphasized the importance of Swiss-Romanian cooperation by stressing that each side can learn from the other, also in the sector of scientific research and environmental protection.

The conference was organized in five half-day sessions, of which each included one keynote lecture, two topic talks, and one or two reports of the ESTROM projects. During the whole conference, 46 posters were on display (ESTROM 2008; Fig. 2). The following sections overview the oral presentations of sessions 1 to 5 and the podium discussion. Detailed reports on the ESTROM projects are presented in separate articles contained in this Special Issue of Environmental Science and Pollution Research (see references). The presentations are also downloadable as digital files (ESTROM 2008). 
Fig. 1 Group picture with participants of the International ESTROM Conference at the Romanian Academy in Bucharest (Photo: Alfredo Alder)

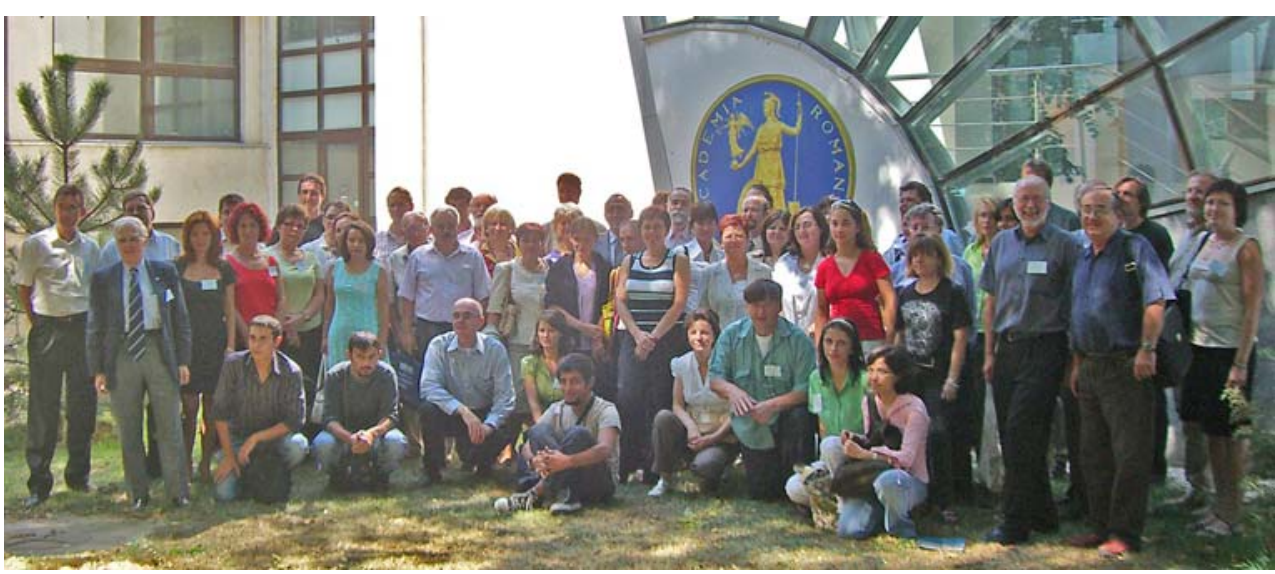

1 The chemical dimension of the EU WFD I-heavy metal pollution by mining and metal producing industries: impacts on rivers, soils, and humans

The keynote speaker, Bernhard Dold (University of Concepción, Chile, and University of Lausanne, Switzerland), overviewed mining activities, emphasizing the environmental impacts due to acid mine drainage. These waters exhibiting high heavy metal concentrations stem from the washout of products formed by the oxidation of pyrite in mining waste deposits, such as tailings and pits. Remediation of abandoned mining sites remains a difficult technical task and causes large and long-term costs. Relocation, reprocessing to gain remaining metals, and final deposition of these materials in a safe way would be a sustainable approach.

Mihaela Sima and Diana Dogaru reported on the ESTROM project EIMAR (see Zobrist et al. 2009), while Liliana Gherghe and Rodica Nicolescu presented the project NEPOLL (Velea et al. 2009).

Ioan Bocsan (University of Medicine and Pharmacy, ClujNapoca, Romania), a member of the ESTROM Steering

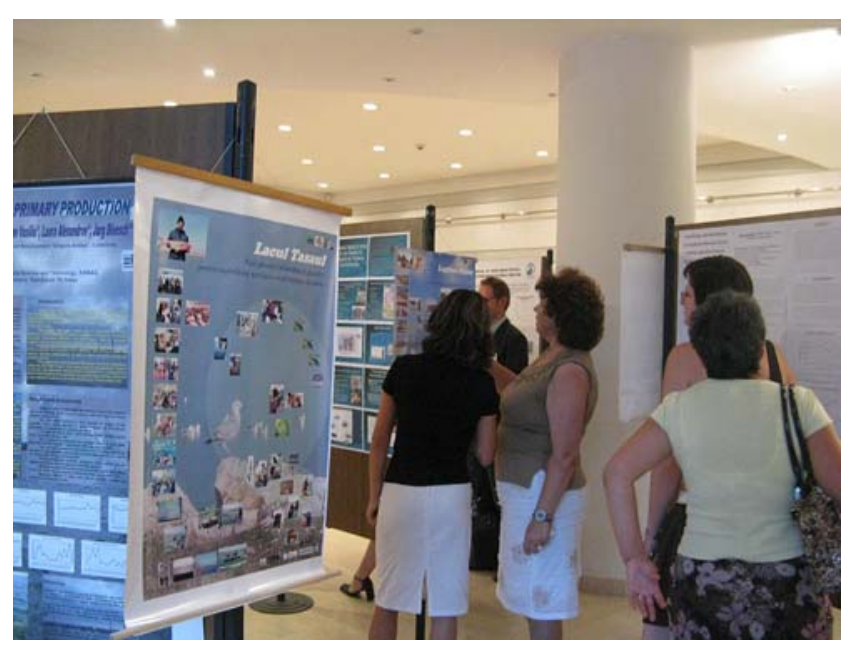

Fig. 2 Poster session at the ESTROM 2009 International Conference (Photo: Laura Alexandrov)
Committee, addressed the question, whether there are clear borders between public health of occupational and environmental exposure to heavy metals in mining areas. Results of two epidemiological studies revealed that such boundaries do not exist. Metallurgical industrial processes create not only potential health hazards for workers involved but also for people living in the vicinity of such industrial plants.

Hong Yang (Eawag, Dübendorf, Switzerland) provided a challenging overview of perception analysis, a socialeconomic topic. The perception of the public toward an environmental pollution problem or risk does not necessarily correspond to scientifically proven facts. Therefore, for implementing socially acceptable measures and policies to mitigate pollution and to reduce health risks, it is essential to analyze and to understand the subjective judgment of people affected.

Horst Behrendt (Institute of Freshwater Ecology and Inland Fisheries, Berlin, Germany; deceased on 26 December 2008) explained, by applying his nutrient emission model MONERIS, that the planned reduction of phosphorous in sewage effluents probably will result in reduced loads of the Danube discharged into the Black Sea that are tolerable to this ecosystem and complies with the EU WFD. For nitrogen, additional measures are needed in the whole Danube Basin to achieve the load levels of 1960 .

\section{The biological and hydromorphological dimension of the EU WFD: to achieve good ecological status}

The keynote lecturer Sebastian Birk (University of DuisburgEssen, Germany) talked about the "Assessment and intercalibration of good ecological status in the Danube River Basin according to EU WFD requirements". He stressed the fact that the ultimate goal of the WFD includes, apart from water quality, biological and hydromorphological aspects, which need to be thoroughly harmonized in terms of methods that are applied in the Danube River Basin countries. Good ecological status of surface waters refers to standardized reference 
conditions and requires legally binding intercalibration according to the WFD. Hence, assessments of surface waters are made comparable between the European countries. The contribution by Jürg Bloesch (Eawag and IAD, International Association for Danube Research, Dübendorf, Switzerland, Fig. 3) stressed the transboundary character and the scientific foundation of integrative strategies applied in EU river basin management. He showed the striking differences between the Danube and the Rhine: While canalization is prominent in the Rhine and Upper Danube, the Lower Danube still features major impact of pollution. Respective river management must be adjusted to the current situation. Ulrich Schwarz (Fluvius, Floodplain Ecology and River Basin Management, Vienna, Austria) provided insight into hydromorphological assessment methods with regard to alterations caused by navigation and hydropower. The Comitée Européen de Normalisation (CEN) standards established in 2004 were illustrated by examples on the Drava/Mura survey of IAD and the Joint Danube Survey 2 performed by ICPDR. Virgil Iordache (University of Bucharest, Romania) focused on the importance of an integrated monitoring system and the implementation of the scientifically based environmental and strategic impact assessments. He pointed toward some weak points of the WFD, the monitoring system in particular. The missing link between monitoring philosophy and environmental costs may be given by the concept of ecosystem services and by applying multicriteria decision and cost benefit analyses. Radu Drobot (Technical University of Civil Engineering, Bucharest, Romania) and Laura Alexandrov (National Institute for Marine Research and Development "Grigore Antipa", Constanta, Romania) presented the ESTROM projects INWAQ (Soutter et al. 2009) and TASAUL (Alexandrow and Bloesch 2009), respectively.

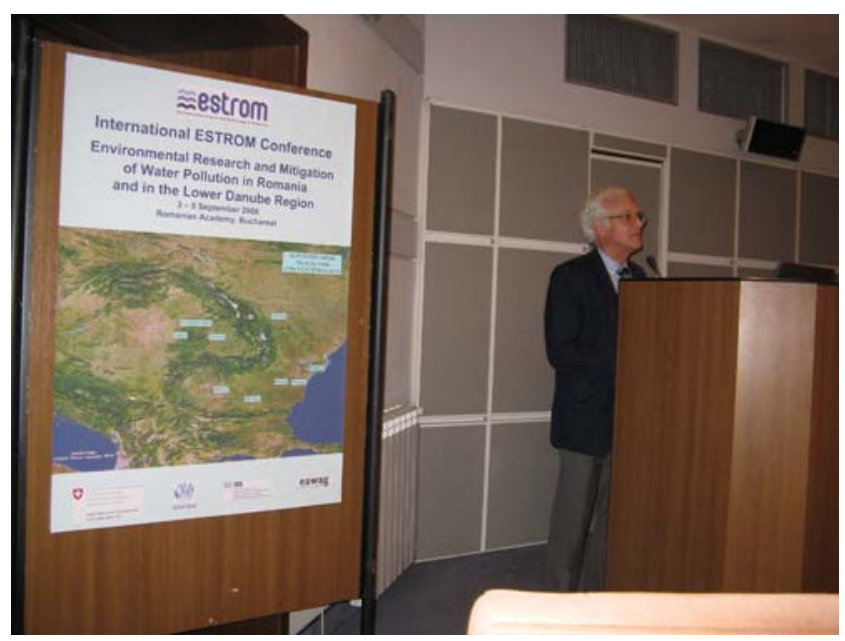

Fig. 3 Topic speaker Jürg Bloesch from Eawag (Switzerland) and the International Associaton for Danube Research (IAD) (Photo: Laura Alexandrov)
3 The chemical dimension of the EU WFD II-organic contaminants, dangerous substances, drinking water, and extrapolation from the Rhine and Meuse to the Danube

Maria Fürhacker (University of Natural Resources and Applied Life Sciences, Vienna, Austria) presented a keynote lecture entitled "EU Water Framework Directive and Stockholm Convention - Can we reach the targets for priority substances and persistent organic pollutants?" She stated that a very valuable frame to approach the targets is provided, but there is still a long way to go to reach them on EU level and on a global scale, respectively (see Fürhacker 2009).

Zaharie Moldovan (National Institute for Isotopic and Molecular Technology, Cluj-Napoca, Romania) and Dumitru Ristoiu (University Babes-Bolyai, Cluj-Napoca, Romania) reported on the ESTROM projects PHARMSOMES (Moldovan and Alder 2009) and WAQUA (Ristoiu et al. 2009), respectively. A topic lecture was presented by Frajo Wirtz (IAWR, International Association of Waterworks in the Rhine catchment area) presenting the "Danube, Meuse and Rhine MEMORANDUM 2008". The memorandum deals with the relationship between surface water quality and drinking water treatment techniques to remove contaminants. This issue now is also respected by the EU WFD. IAWR strongly supports all attempts to avoid inputs of hazardous substances into the Rhine and Danube River Basins (Wirtz 2009). Romeo Chira (Somes Water Company, Cluj-Napoca, Romania) presented an overview talk on "Drinking water resources and treatment in Romania". In Romania, rivers provide about $85 \%$ of the drinking water supply, and hence, water quality is of crucial importance for human health. This is even more important when considering that $35 \%$ of the population has no access to public drinking water supply, and $47 \%$ is not linked to wastewater treatment plants.

\section{Sediments, mercury, and persistent and polar organic pollutants}

Ivan Holoubek (Masaryk University, Brno, Czech Republic) reported in his talk "Monitoring persistent organic pollutants in Central and Eastern Europe" on a project initiated in 2006 with the goal of developing monitoring capacity in Eastern Europe, where many countries suffer the lack of data on concentrations of persistent organic pollutants in the environmental matrices. This absence of information is preventing the local authorities from taking the adequate actions to protect people and the environment. Andrea Garcia Bravo (University of Geneva, Switzerland) and Ioan Manuel Ciumasu (Alexandru Ioan Cuza University, Iasi, Romania) reported on the ESTROM projects ORSED (Bravo et al. 2009) and POPIASI (Neamtu et al. 2009), respectively. 
Frank Thomas Lange (Technologiezentrum Wasser, Karlsruhe, Germany) lectured on "Perfluoroalkyl sulfonates and carboxylates in ambient waters and in drinking water". Perfluorinated compounds (PFC) enter the aquatic environment through industrial and municipal wastewaters, accidental spills, e.g., by fire-fighting activities, leaching of contaminated solid waste disposals, and airborne deposition. Therefore, they are found ubiquitously in ground and surface waters, which are used for drinking water. Due to the bioaccumulation potential and the toxic properties of some PFC combined with their outstanding recalcitrance and high polarity, they are of extraordinary relevance for the waterworks. The example of PFC residues in drinking water tell us that in the future, prior to the release of a new chemical onto the global markets, the concerns of the water works regarding the removal efficiency of chemicals by natural processes should play a more important role than in the past. In May 2009, perfluorinated octylsulfonate was included in the list of persistent organic pollutants, which are regulated by the Stockholm convention of the United Nations.

Marijan Ahel (Rudjer Boskovic Institute, Zagreb, Croatia) talked on "Surfactants and surfactant metabolites in wastewaters and ambient waters". It was an illustration of the importance of a comprehensive analytical approach in the environmental risk assessment of surfactants, by focusing on two prominent aromatic surfactants: the anionic linear alkylbenzene sulphonates and nonionic alkylphenol polyethoxylates. Examples of surfactant behavior and mass balance studies in sewage treatment plants and in river waters were shown by taking into account both physicochemical partitioning between dissolved and particulate phases and metabolic patterns.

A podium discussion dealt with the topic "How to implement the issue of dangerous substances within the EU-WFD in the Lower Danube River Basin?", chaired by Mihaela Popovici (International Commission for the Protection of the Danube River, ICPDR, Vienna) as moderator and with Margareta Nicolau (Romania), Elena Tuchiu

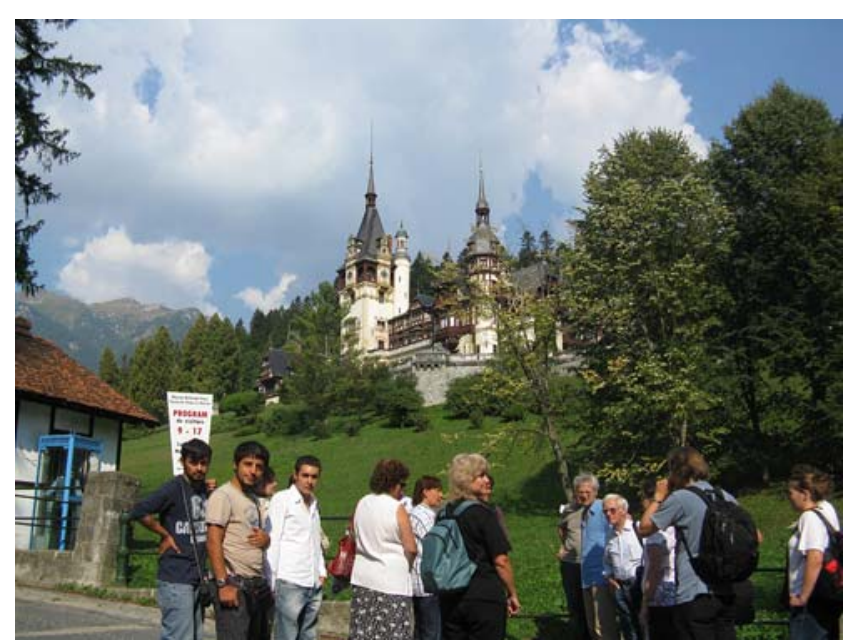

Fig. 5 Conference participants visiting the Peles castle (Photo: Laura Alexandrov)

(Romania), and Thomas Rauchbüchl (Austria) as panel members (Fig. 4). Key subjects of discussion were scientifically based monitoring, data quality control (ring tests), making data banks public, emission control of industry, and legal aspects and public participation. Although the experts and audience vividly debated the hot issue of political implementation, the podium could not achieve an ultimate resolution. However, the stimulating exchange of ideas and opinions provided suggestions of realistic solutions that might be even considered by respective authorities and by the ICPDR on the basin level.

\section{Biogeochemistry and local and global impacts in the Lower Danube River Basin}

The keynote lecture was given by Hans Peter Nachtnebel (University of Natural Resources and Applied Life Science, Vienna) on "Interaction between hydrological and ecosystems processes in alluvial flood plains". This overview presentation summarized session 2 by stressing the hydro-
Fig. 4 Podium discussion: Mihaela Popovici (ICPDR, Vienna) as moderator and Elena Tuchiu (Romania) and Thomas Rauchbüchl (Austria) as panel members (Photo: Laura Alexandrov)

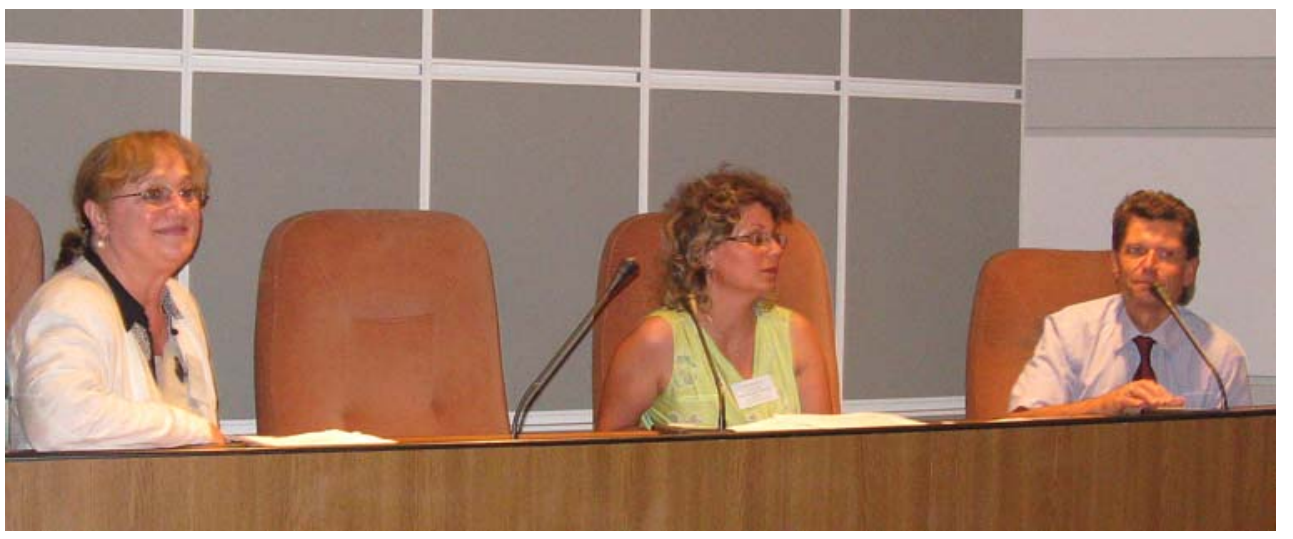


logical and ecological importance of floodplains, especially in the Lower Danube Basin. Floodplain research must consider hierarchical spatial and temporal scales, different interfaces between aquatic and terrestrial ecology, and an applied transdisciplinary approach. The ecosystem services of floodplains threatened by various human impacts encompass, among other, water, sediment and nutrient retention as well as habitat and biological diversity. Silviu Radan and Alina Pavel (GeoEcoMar, National Institute of Marine Geology and Geoecology, Bucharest, Romania) presented results of the ESTROM project WASEDY (Pavel et al. 2009).

Talks given by Cristina Sandu (Academia Romana, Institute of Biology, Bucharest, Romania) and Artem Lyashenko (National Academy of Ukraine, Institute of Hydrobiology, Kyiv, Ukraine) entitled "Ecological impacts of dredging the Bystroe Channel" as well as that of Orieta Hulea (WWF Danube Carpathian Programme, Bucharest, Romania) entitled "Lower Danube Green Corridor: Protected areas and human impacts" stressed the impacts by navigation in the Danube Delta (Bystroe Channel) and the Lower Danube. Both areas are under protection at the national and international levels (Danube Delta UNESCO Biosphere Reserve, Green Corridor Natura 2000 site), which is often undermined by unsustainable developments. While the Green Corridor is mainly affected by hydrotechnical engineering impacting on floodplain- and hydromorphology, pollution in the Delta is still prominent.

\section{Summary and outlook}

The conference was closed by a presentation on "ESTROM Review and outlook including the conference summary" by Walter Giger, the Chairman of the ESTROM Steering Committee. The ESTROM Programme provided successful scientific cooperations between partners in Romania and Switzerland (Panin and Giger 2008, Giger and Panin 2009). It helped to establish a network that has potential for future cooperation as shown by the call for the new SCOPES Programme 2009-2012. The conference as well as the three joint project meetings strengthened personal relationships that were also cultivated at the conference dinner with a special award ceremony and during an excursion to the Peles and Bran castles (Fig. 5).

Acknowledgments The ESTROM 2009 International Conference was generously supported by SDC, the Swiss Agency for Development and Cooperation, which allowed awarding travel grants to about 20 young researchers from Romania and other Eastern European countries.
Additional funding came from the Romanian Ministry of Education, Science and Youth, which in particular allowed the publication of a proceedings issue in GeoEcoMarina (Panin and Giger 2008). Several Swiss participants were supported by a conference grant of Eawag, the Swiss Federal Institute of Aquatic Science and Technology.

\section{References}

Alexandrow ML, Bloesch J (2009) Eutrophication of Lake Tasaul, Romania-proposals for rehabilitation. Environ Sci Poll Res 16(Suppl 1):42-45

Bravo GA, Loizewau JL, Ancey L, Ungureanu VG, Dominik J (2009) Historical record of mercury contamination in sediments from the Babeni Reservoir in the Olt River, Romania. Environ Sci Poll Res 16(Suppl 1):66-75

ESTROM (2008) International ESTROM Conference: Environmental Research and Mitigation of Water Pollution in Romania and in the Lower Danube Region. Book of Abstracts, $164 \mathrm{pp}$ and presentations (www.estrom.ch).

Fürhacker M (2009) EU Water Framework Directive and Stockholm Convention - Can we reach the targets for priority substances and persistent organic pollutants? Environ Sci Poll Res 16(Suppl 1):9297

Giger W, Panin N (2009) ESTROM, Environmental science and technology in Romania - a programme overview. Environ Sci Poll Res 16(Suppl 1):3-8

Moldovan Z, Alder AC (2009) Environmental exposure of pharmaceuticals and musk fragrances in the Somes River before and after upgrading the municipal wastewater treatment plant Cluj-Napoca, Romania. Environ Sci Poll Res 16(Suppl 1):46-54

Neamtu M, Ciumasu IM, Costica N, Costica M, Bobu M, Nicoara MN, Catrinescu C, Becker van Slooten K, De Alencastro LF (2009) Chemical, biological, and ecotoxicological assessment of pesticides and persistent organic pollutants in the Bahlui River, Romania. Environ Sci Poll Res 16(Suppl 1):76-85

Panin N, Giger W (2008) Proceedings of the Romanian-Swiss cooperative research programme 'Environmental Science and Technology in Romania' (ESTROM). Geo-Eco-Marina 14: 1-95, www.geoecomar.ro/publications

Pavel A, Durisch-Kaiser E, Balan S, Radan S, Sobeck S, Wehrli B (2009) Sources and emission of greenhouse gases in Danube Delta lakes. Environ Sci Poll Res 16(Suppl 1):86-91

Ristoiu D, von Gunten U, Mocan A, Chira R, Siegfried B, Kovats MH, Vancea S (2009) Trihalomethane formation during water disinfection in four water supplies in the Somes river basin in Romania. Environ Sci Poll Res 16(Suppl 1):55-65

Soutter M, Alexandrescu MI, Schenk C, Drobot R (2009) Adapting a geographical information system-based water resource management to the needs of the Romanian water authorities. Environ Sci Poll Res 16(Suppl 1):33-41

Velea T, Gherghe L, Predica V, Krebs R (2009) Heavy metal contamination in the vicinity of an industrial area near Bucharest. Environ Sci Poll Res 16(Suppl 1):27-32

Wirtz F (2009) Danube, Meuse and Rhine Memorandum 2008. Environ Sci Poll Res 16(Suppl 1):112-115

Zobrist J, Sima M, Dogaru D, Senila M, Yang H, Popescu C, Roman C, Bela A, Frei L, Dold B, Balteanu D (2009) Environmental and socioeconomic assessment of impacts by mining activities - a case study in the Certej River catchment, Western Carpathians, Romania. Environ Sci Poll Res 16(Suppl 1):14-26 